\title{
Relevant Issues Regarding The Delivery Of Database Courses Through Distance Education
}

George Garman, (email: garmang@mscd.edu), Metropolitan State College of Denver

\begin{abstract}
This paper discusses the issues that were involved in the development of two online database courses at The Metropolitan State College of Denver. These courses are CMS 3060 Database Management Systems and CMS 4060 Advanced Database Management Systems. In addition to the issues apparent in the development of regular courses, technology driven courses provide a special set of problems. This paper examines the integration of a remote relational database management system (Oracle) into an online course. Also, the paper discusses the use of the PC based Oracle Developer 2000 product in an online course.
\end{abstract}

\section{Introduction}

Distance education is rapidly becoming an integral part of the academic landscape. Colleges across the country are offering a significant share of their curriculum online. The Metropolitan State College of Denver is a nonresidential, undergraduate college sharing the physical campus with the University of Colorado at Denver and the Community College of Denver. This urban campus experiences all of the pressures caused by the rapid growth in educational demands during the past decade. The infrastructure is being pushed past its capacity with classroom and office space at its limits. Parking for this commuter campus is at a premium. Although two new buildings have been erected in the past few years, future expansion of the physical site is severely limited because the size of the campus is "locked" by the city of Denver. To reduce stress on the physical facilities and to continue to provide for growth, Metro State has undertaken an initiative to provide quality online courses. These courses are designed, developed and delivered by full-time faculty within the College.

At the Metropolitan State College of Denver, each semester approximately 200 courses are delivered by resident faculty through the Jones e-education $(\odot$ service. Students will find enough courses online to satisfy all of their general studies requirements. The School of Business offers all of the required courses to satisfy the business school core requirements online.

The Department of Computer Information Systems is the largest department in the College. It offers 24 courses and currently supports about 1100 majors and 150 minors. While not all 24 courses are offered online, the department offers enough courses to allow majors to complete their entire degree program online. In addition, the Computer Information Systems' Department offers five certificates that may be completed online. This demonstrates the strong commitment of the College, School of Business, and Department of Computer Information Systems to delivering quality education to the students.

This paper concerns the issues that were involved in the online delivery of two courses: CMS 3060 Database Management Systems and CMS 4060 Advanced Database Management Systems. These courses presented some special problems. Both are driven by the Oracle RDBMS system that resides on the Metro State host computer. In addition, CMS 4060 employees a PC side software package called Developer 2000.

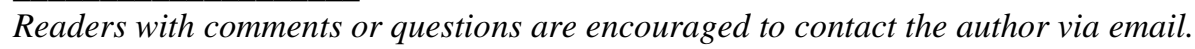


Although Developer 2000 is installed in Labs throughout the campus, the software would need to be accessible to the distance learner.

\section{Designing an Interface.}

Several factors were important in the development of the course home page including:

- An orientation for new students.

- Quick access to assignments.

- $\quad$ Access to the external links to database student resources.

- Access to course announcements.

- A link that would allow the student to track grades.

- A seamless (or nearly seamless) access to the Relational Database Management System.

- $\quad$ Links to the College and Departmental web pages.

- $\quad$ Provide an E-mail link to the instructor.

A navigation bar at the top of each page provides links to the Syllabus, Assignments, Student Resources, SQL, Grades, and Announcements. Each page has a footer containing the copyright notice. The footer also has links to the instructor's e-mail, the department home page, and the college home page. The course home page also contains links to the Getting Started module and the instructor's personal home page. See figure 1 for a display of the course home page.

Figure 1

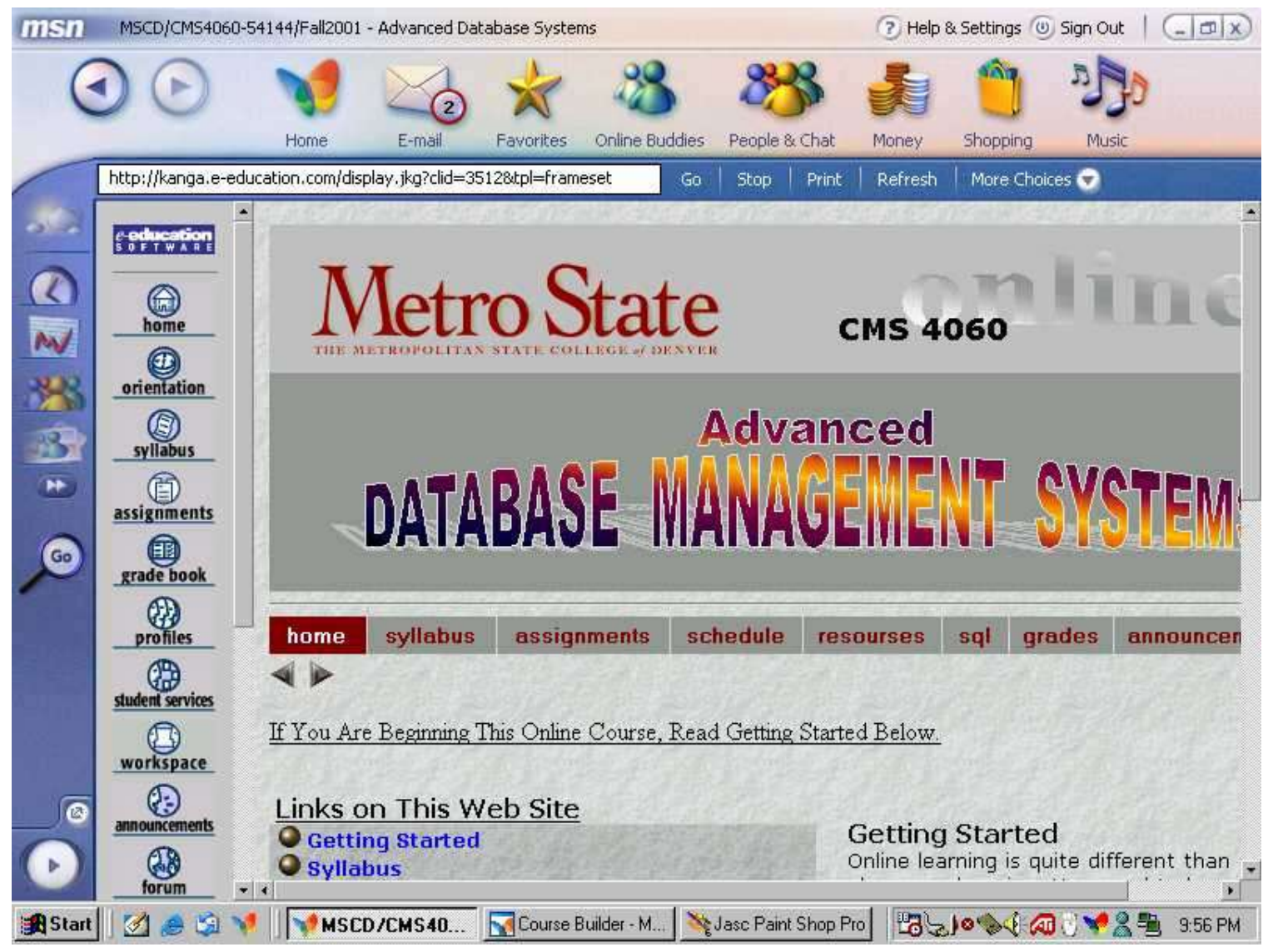




\section{Performance Assessment.}

Assessing student performance in an online course presents a set of concerns absent in live classes. The instructor generally receives little or no direct feedback from students. It isn't always clear who completed the submitted assignments. Online examinations are relatively easy to construct and administer but are subject to abuses by students. Unauthorized notes, books, etc. can easily be used to assist the student with the examination. Another possibility is that a group of students might collectively view the examination when a single student takes it. I use both the online format for quizzes but require the students to sit for examinations at a testing center where positive identification is required.

Distance learners are evaluated on the basis of weekly assignments and three examinations spread evenly throughout the semester. The weekly assignments are evaluated at approximately ten points each. Each examination is valued at 150 points. This means that the examinations account for seventy-five percent of the final average and the assignments account for twenty-five percent. The assignments are widely varied. Some assignments involve completing a well-defined project with defined goals. Other assignments require the student to complete an online multiple-choice or matching quiz. To avoid academic dishonesty, students are required to complete examinations in a proctored environment. Most students complete examinations at the school's Testing Center. Students who reside in more distance locations must make arrangements with a local junior college or library to have the examination monitored.

\section{Accessing the College DBMS}

Since the Oracle database software resides on the school's host computer, these database courses necessitate access to the school's system. In designing this course, I tried to make this access as seamless as possible. Since all students have an account on the host computer, I created a telnet link directly from all pages on the web site. Although telneting to the host computer is somewhat slower than direct access, this access allows students to view the web pages (especially the tutorials) in one window while having access to the database software in another window. Students can view SQL queries, for example, change windows, and run the query immediately. Script files are easily scraped from the web page and copied directly into files on the host computer. This methodology provides a learning environment that may even be better than live instruction.

CMS 4060 provides an even larger challenge. Much of the course is driven by Oracle's Developer 2000 software. This software must reside on the student's personal computer. Two years ago, the Oracle Corporation introduced a program that allows students to install the software on their own computers as long as it's used for educational purposes only. This program, called the Oracle Academic Initiative, also provides other benefits to students including a job market database and substantially reduced fees for students who want to sit for Oracle's certification examinations. The Oracle Academic Initiative also provides significantly reduced tuition for faculty members who enroll in Oracle's training courses and provides the faculty members with a variety of course material. Under the Oracle Academic Initiative, we distribute the software to students for a minimal charge (to cover the cost of the CD and copying). By establishing an alias, students in the CMS 4060 course can easily access the host computer while continuing to work with the course web site.

\section{Useful Resources.}

The database field has expanded greatly within the past several years. Database concepts have grown to include object-oriented methodologies, complex data types, user defined data types, and spacial databases. The database courses now touch on a variety of topics including data warehousing and database-driven web sites. Security has now become a major consideration. These concepts involve a depth that cannot be fully explored in the regular curriculum. The courses are supplemented with an extensive resource page containing links to a plethora of database related sites. The resource page also contains some more practical links including job boards and online textbook vendors. Figure 2 shows the student resource page. 


\section{Designing Tutorials}

Several tutorials have been developed around basic SQL procedures. The tutorials written for CMS 3060 take the student through the table creation process, querying tables, creating views, altering tables, modifying data,

Figure 2

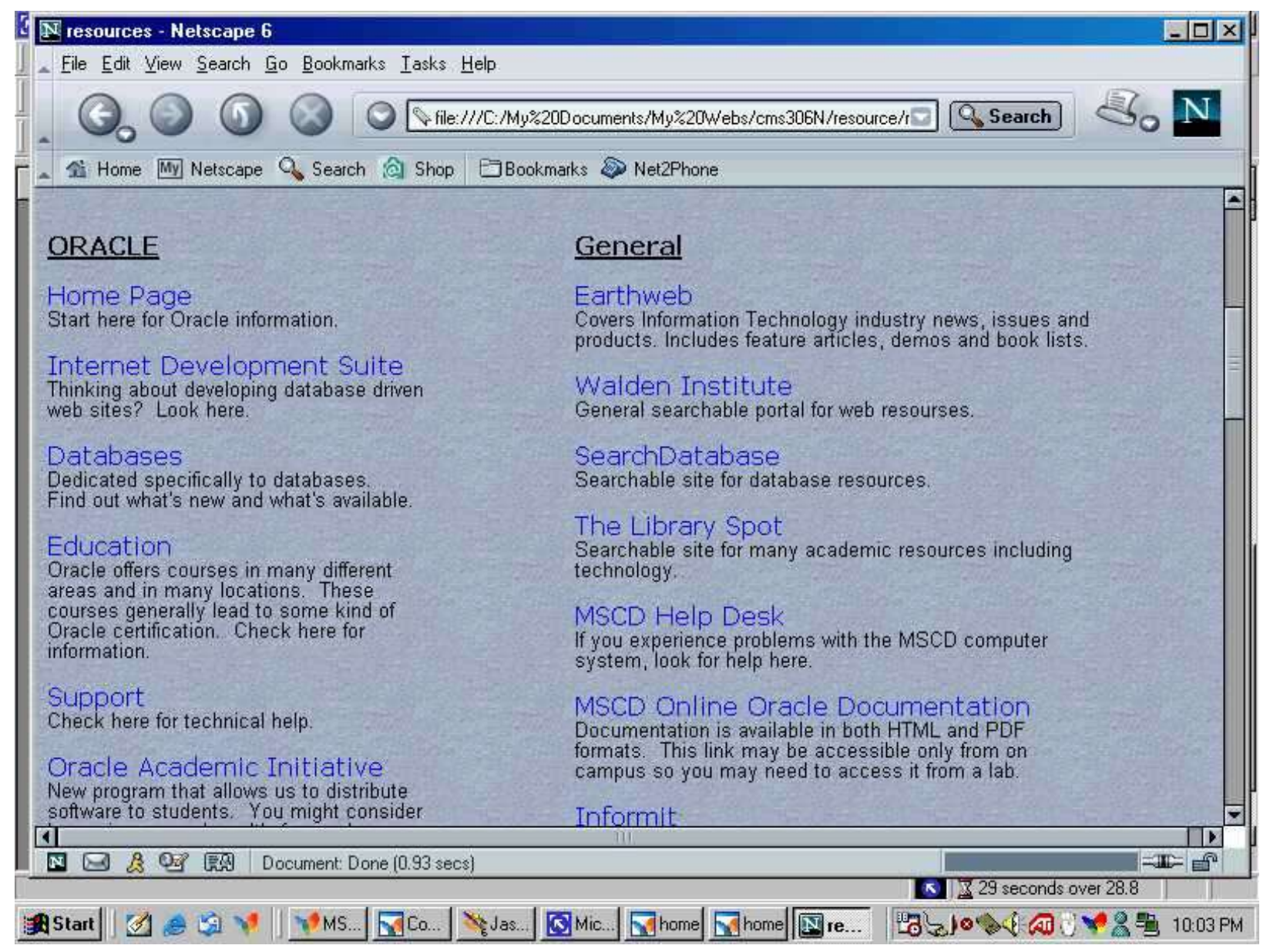

and reporting. The tutorials written for CMS 4060 concentrate on the use of PL/SQL to write procedures, triggers, and functions. Each tutorial is written in a manner so that the concepts are presented sequentially with each page building upon the concepts described in the last. A sidebar menu allows direct access to any page in the tutorial to expedite review of a single concept. The student will normally have simultaneous access to both the tutorial pages and the RDBMS during a session. By switching windows, the examples from the tutorial can be attempted immediately. This immediate implementation of new concepts may be superior to conventional classroom instruction. CMS 3060 contains ninety tutorial pages and CMS 4060 contains forty-two tutorial pages. Figure 3 presents an example of a tutorial page. 
Figure 3

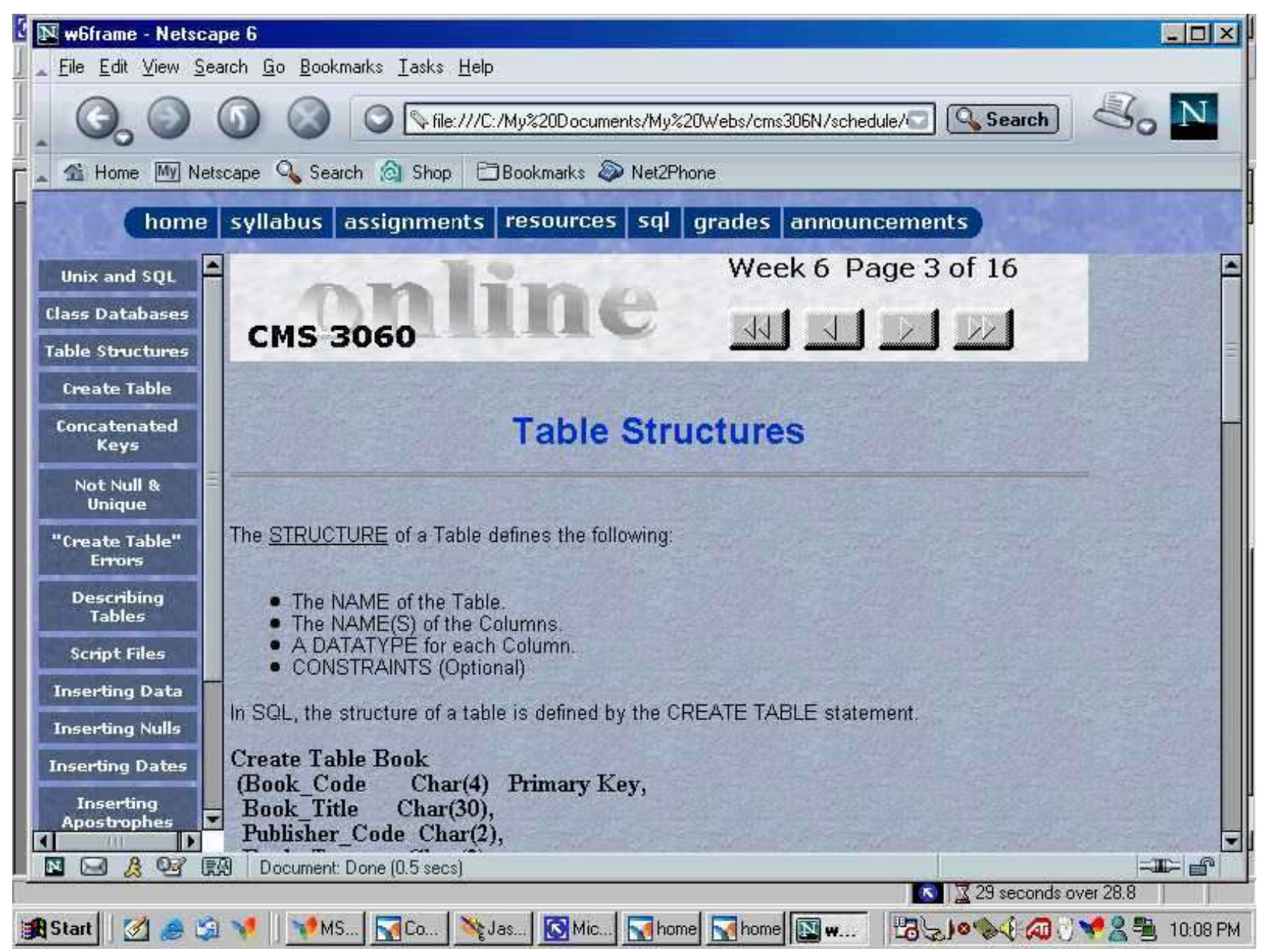

\section{Communicating With Students}

Information is disseminated from the college to students through an announcement link that is automatically displayed when the student logs onto the site. Students receive information concerning items such as system availability and testing schedules at this time.

Students submit questions for the instructor through e-mail. Courses average about twenty-five questions per week per section from students. I access e-mail several times per day. Instructors hold about one hour of online office hours per week. Also, online students are welcome to visit during regular office hours. I have the pleasure of meeting about one-half of my online students each semester. Assignments may be submitted through e-mail or through the workspace provided by Jones e-education $\odot$. The vast majority of the students prefer to submit through E-mail.

The course announcement page is the primary vehicle for disseminating information from the instructor to the students. The announcement link provides the student with all relevant information concerning developments in the course. The announcement link provides information such as hints for examinations and scheduling changes. The announcement page also contains links to the answers to assignments. E-mail is also used to inform students of general information and to distributed documents that are not in text format. Oracle script files and some Developer 2000 files are distributed through E-mail. 
All students are required to complete a profile during the first week of the semester. This is part of the first assignment and students who do not complete the profile receive zero points for the first assignment. The profile asks for some personal items as a way of introducing themselves to others. Among the questions are work related information, family status, a list of priorities, and a request for an interesting anecdote. The students are also asked to describe the hardware and software used to access the web site. The attitude towards the classmates is often readily apparent through the information contained in the profile. Some students provide as little information as possible giving only their names and e-mail addresses. Others feel compelled to relate their entire life stories complete with pictures of themselves and their families. Requiring the students to complete the profile allows the instructor to have some semblance of a live class. In some respects, I feel that I know many students in the online class better than my students in live classes.

Jones e-education ${ }^{\odot}$ provides a chat room that can be initiated by any student or by the instructor. The chat room allows the participants to establish an interactive real-time dialog. Some students benefit greatly from interaction with other students. Others, perhaps most, would view chat as an unnecessary demand on their time if required to participate. Chat provides an important outlet for those students who feel the urge to participate with other students. Students are invited to participate in the chat room but are not required to do so. Jones e-education ${ }^{\odot}$ also offers a multithreaded feature, called forum, that allows students or the instructor to post questions or comments and respond to posted information. In many ways, forum is a more useful communication tool than chat. Students are not required to be present at a given time to use this feature. Forum allows everyone to take the time to form a more thoughtful response than does chat. Forum messages do not go away until the end of the semester. Students are encouraged to use Forum but are not required to do so. Each semester several messages are posted, most of a personal, rather than academic, nature.

\section{Monitoring Student Activity}

Jones e-education $^{\odot}$ monitors all student activity and provides several useful reports for the instructor. Following are the reports that the instructor may generate.

Report Name
Course Roster
Hits by URL
Users Logged On
Student Log
Student Time

The Hits by URL, Student Log, and Student Time reports contain highly desirable information but become very long. I run these reports and maintain the data for future research purposes at the end of each semester. Downloading the information requires the better part of a day.

\section{Conclusions}

Designing and implementing distance education courses require much thought and preparation. Especially difficult is the design of courses requiring the use of technology. Database courses can be constructed online in a manner that incorporates other technologies. The database courses at The Metropolitan State College of Denver allow for an almost seamless integration of the course web site with the Oracle relational database management system.

\section{References}

1. Garman, George, "On-line Course Development for Database Courses", The International Business and Research Conference Proceeding, October 2001, Reno, Nevada. (distributed on CD ROM).

2. Weisberg, M., "Guidelines for Designing Effective and Healthy Learning Environments for Interactive Technologies," Interpersonal Computing and Technology Journal, Volume 1, Number 3, 1993.

[http://www.helsinki.fi/science/optek/]. 
